\title{
Prevalência da coinfecção dos vírus das hepatites B e D em estudantes de graduação em uma universidade em Belém, Pará, Brasil
}

\author{
Prevalence of the coinfection of the hepatitis $B$ and Delta viruses among graduates at an university \\ in Belém, Pará, Brazil
}

Prevalencia de la coinfección de los virus de las hepatitis B y Delta em graduados de una

universidad de Belém, Pará, Brasil

Recebido: 24/11/2021 | Revisado: 01/12/2021 | Aceito: 03/12/2021 | Publicado: 13/12/2021

\author{
Rômulo Silas Souza Crispim \\ ORCID: https://orcid.org/0000-0003-2060-0153 \\ Universidade da Amazônia, Brasil \\ E-mail: romulocrispim98@gmail.com \\ Carla De Castro Sant'Anna \\ ORCID: https://orcid.org/0000-0002-7171-7071 \\ Universidade da Amazônia, Brasil \\ E-mail: santannacarla@yahoo.com.br \\ Érika Cristina Pinheiro Tavares Santos \\ ORCID: https://orcid.org/0000-0002-6175-3001 \\ Universidade da Amazônia, Brasil \\ E-mail: erika.pin.heiro@hotmail.com \\ Carla Carolina Corrêa Pantoja \\ ORCID: https://orcid.org/0000-0001-7672-2649 \\ Universidade da Amazônia, Brasil \\ E-mail: pantojacorreacarol@gmail.com \\ Marcella Kelly Costa de Almeida \\ ORCID: https://orcid.org/0000-0002-3376-0976 \\ Universidade da Amazônia, Brasil \\ E-mail: mkca02@outlook.com
}

\begin{abstract}
Resumo
Introdução: Os Hepadnavirus humanos são vírus que causam grave adoecimento do fígado, órgão essencial ao perfeito funcionamento do corpo humano; esse processo se traduz nas hepatites virais, que, no Brasil, acometem ainda um elevado número de pessoas. Objetivo: Este trabalho tem como objetivo demonstrar a prevalência e características epidemiológicas das hepatites B e D em alunos de graduação em uma Instituição de Ensino Superior em Belém, Pará, Brasil. Materiais e métodos: Este é um estudo transversal, quantiqualitativo. Foi aplicado aos participantes questionário para coleta de dados sobre estilo de vida e teste imunocromatográfico que, em caso de resultado reagente para Hepatite B (HBsAg presente) neste, seria performada coleta de sangue para posterior análise através do ensaio imunológico ELISA em busca da presença do antígeno HDVAg. Resultados: Foram incluídos 100 participantes, sendo 44 (44\%) do sexo feminino, e $56(56 \%)$ do sexo masculino. Nenhum participante obteve resultado reagente para Hepatite B. Onze $(11 \%)$ dos Participantes relataram já terem tido alguma hepatite, enquanto 88 (88\%) dos Participantes relataram nunca terem tido a doença. Nenhum caso de hepatite D foi detectado. Conclusão: A prevalência de casos ativos (agudos) de Hepatite B e/ou D na comunidade acadêmica é nula, porém, mais de $10 \%$ dos participantes declararam já ter tido algum tipo de hepatite. Os dados demonstram a eficácia da vacina contra a hepatite B.

Palavras-chave: Hepatite Viral Humana; Vírus da Hepatite B; Vírus da Hepatite D; HBsAG; HDVAg; Virologia; Imunologia.

Abstract

Introduction: The human Hepadnavirus are a kind of viruses responsible for the severe ailment of the liver, an essential organ for the perfect operation of the human body; this process happens as the viral hepatitis, which in Brazil, still reaches na elevated number of individuals. Objective: This research intends to demonstrate the prevalence and epidemiologic characteristics of the Hepatitis B and Delta viruses in graduates at na University in Belém, Pará, Brazil. Materials and methods: This is a transversal study in which the academicians of the University Of Amazon, from the Alcindo Cacela campus whose attended the inclusion and exclusion criteria, willingly volunteered to participate in the research. The participants were applied a questionnaire to gather lifestyle information and immunochromatographic assay that, in the case of reactive result for hepatitis B, was to be followed by a blood sampling for posterior use in the ELISA assay in search of the HDVAg antigen. Results: 100 participants were included in this study, of which 44 (44\%)
\end{abstract}


of the participants were female, and $56(56 \%)$ male. There was detected no cases of hepatitis Delta in the population involved. Conclusion: The prevalence of active (acute) cases of hepatitis B and/or Delta in the academic community is null, however, over $10 \%$ participants stated to have already had contact with hepatitis.

Keywords: Human Viral Hepatitis; Hepatitis B virus; Hepatitis Delta virus; HBsAg; HDVAg; Virology; Immunology.

\section{Resumen}

Introducción: Los Hepadnavirus son virus que causan graves enfermedades al hígado, un órgano esencial para el funcionamiento del cuerpo humano. Ese proceso se traduce en las hepatitis virales, que aún enferman a una gran cantidad de personas en Brasil. Objetivo: Este trabajo busca aclarar la prevalencia y las características epidemiológicas de las hepatitis B y Delta en alumnos de graduación en uma Institución de Enseñanza Superior en Belém, Pará, Brasil. Materiales y métodos: Este es un estudio transversal, donde los alumnos de los cursos de graduación de la Universidad de la Amazonía - UNAMA - instalaciones Alcindo Cacela, participan voluntariamente y cumplen los criterios de inclusión y exclusión descritos. Los participantes respondieron a un cuestionario para recolección de datos sobre estilo de vida y teste imunocromatográfico, que, en el caso de un resultado reactivo para hepatitis b (presencia de HBsAg), se realizaría la recolección de sangre para un análisis más detallado mediante inmunoensayo ELISA en busca de la presencia del antígeno HDVAg. Resultados: Participaron 100 estudiantes, de los cuales, 44 (44\%) del sexo femenino y $56(56 \%)$ del sexo masculino. Ningún participante obtuvo resultado reactivo para Hepatitis B. Once (11\%) de los participantes informaron que ya se enfermaron con alguna hepatitis, mientras 88 (88\%) de los participantes informaron que nunca se enfermaron. Ningún caso de hepatitis D fue detectado. Conclusión: la prevalencia de casos activos (agudos) de hepatitis B y/o D em la comunidad académica es zero, todavía, más de 10\% de los participantes informaron que ya tuvieron contacto con las hepatitis.

Palabras clave: Hepatitis Viral Humana; Virus de la Hepatitis B, Virus de la Hepatitis D, HBsAg; HVAg, Virología, Inmunología.

\section{Introdução}

O Vírus da Hepatite B (VHB) é um vírus do grupo dsDNA-RT e faz parte do gênero taxonômico Orthohepadnavirus, da família Hepadnaviridae (Liang, 2010). O Comitê Internacional de Taxonomia dos Vírus (ICTV) descreve que dento da família do VHB são encontrados dois gêneros: Ortohepadnavirus e Avihepadnavirus, que infectam respectivamente mamíferos e aves. (ICTV, 2019). O grupo dsDNA-RT, onde o VHB está inserido, incorpora vírus de DNA de fita dupla que sintetizam por meio da transcriptase reversa, moléculas de fitas simples de RNA de sentido positivo (+ssRNA) (Vieira, 2016).

O Vírus da Hepatite D (VHD) é classificado taxonomicamente como o único membro da única espécie dentro do gênero Deltavirus, e até o presente momento, não possui classificação de Família devido à sua natureza única e complexa: o VHD é um vírus-satélite, ou seja, é uma partícula viral que depende de outros vírus mais complexos para completar o seu ciclo viral e por isso, neste caso, utiliza de partículas como os receptores no antígeno de superfície do VHB (HBsAg) para a composição do seu envelope (Magnius et al., 2018). Contida nesta camada superficial, há uma ribonucleproteína composta pelo genoma de RNA do HDV, e aproximadamente setenta cópias de duas proteínas virais, uma grande (Large) e uma pequena (Small): HDAg-L e HDAg-S que, respectivamente, são responsáveis pela produção do envelope, pela replicação viral, dentre outras funções regulatórias (Magnius et al., 2018; Rizetto, 1989; Bergmann \& Gerin, 1986).

Estudos epidemiológicos realizados em diversas partes no mundo mostram a presença de 291 a 297 milhões de portadores crônicos de Hepatite B (HB), e que 48 a 60 milhões estão coinfectados pelo VHD (Beudeker et al., 2021; Duarte, 2021; Barros, 2020; Stockdale et al., 2020; Shen et al., 2018; Oliveira et al., 2017; Scaglione \& Lok, 2012; Wedemeyer \& Manns, 2010).

De acordo com o Boletim Epidemiológico das Hepatites Virais de 2020 publicado em 2021 pelo Departamento de Doenças de Condição Crônica e Infecções Sexualmente Transmissíveis, na região norte do Brasil, foram notificados no Sistema de Informação de Agravos de Notificação (SINAN) 104 casos de Hepatite D (HD) e 2.471 casos de HB; em 50,38\% dos casos de HD, os infectados eram pessoas entre 20 e 39 anos, e a classificação clínica com o maior número percentual é a forma crônica da doença $(75,60 \%)$. No mesmo Boletim, dos 104 casos de HD notificados na região norte, apenas 04 estão no Pará. O total notificado no estado entre os anos de 1999 a 2019 é de 69 casos (Brasil, 2020). 
A HB manifesta os seus primeiros sintomas clínicos entre 45 a 180 dias na forma aguda da doença, e estes sintomas se mostram na maioria dos casos como cansaço excessivo, icterícia, dor abdominal, tontura e, ainda, em alguns poucos casos, a doença pode ser anictérica e não causa sintomas perceptíveis pelo enfermo (Brasil, 2020; Ferreira, 2000).

A superinfecção com o VHD ocorre pelas mesmas vias que a infecção pelos outros agentes causadores das hepatites, se diferenciando pelo adoecimento mais rigoroso do fígado ao causar quadros fulminantes e crônicos da doença (Urban et al., 2021; Huang, \& Lo, 2014; Cross et al., 2008).

No Brasil, em 2019, houveram 1.100 casos confirmados de HB entre pessoas com níveis de escolaridade superior completo e incompleto. Destes, pouco mais da metade incidem sobre a população masculina: 53,45\% (N=588), enquanto 46,55\% $(\mathrm{N}=512)$ são casos entre mulheres. Ademais, entre os casos gerais de HB, predominam as infecções por vias sexuais (20,4\% dos casos), domiciliar (3,0\% dos casos), pelo uso de drogas (1,4\% dos casos) e transfusionais (1,3\% dos casos) (Brasil, 2020).

Desde 1999 até 2019, período de existência dos Boletins Epidemiológicos publicados pelo Ministério da Saúde, foram registrados 4.156 (quatro mil cento e cinquenta e seis) casos de HD, e destes, 3.143 (três mil cento e quarenta e três) casos se manifestaram na forma crônica.

No Brasil, existem cerca de 5,8 milhões de estudantes matriculados em mais de 2.500 Instituições de Ensino Superior (Andrade et al., 2011), e a grande maioria da população universitária, tanto no Brasil como no mundo, é constituída por pessoas que praticam ativamente atividades sexuais (Castro et al., 2019). Em média, o número de parceiros sexuais de um estudante universitário varia entre 1 e 15 (Alves, 2017; Falcão, 2007).

O consumo de bebida alcoólica é também um fator crucial para o comportamento de risco: quando consumido em excesso, favorece o desuso de preservativo durante as relações sexuais e também a transmissão de Infeccões Sexualmente Transmissíveis (ISTs) como as Hepatites, que também são consideradas ISTs (OMS, 2021; Cardoso, et al., 2008)

Desta forma, o presente estudo teve o objetivo de determinar prevalência das coinfecções dos vírus das HB e HD em acadêmicos de uma Instituição de Ensino Superior na cidade de Belém, capital do estado do Pará.

\section{Metodologia}

Trata-se de um estudo do tipo transversal descritivo, de modo quantitativo que aconteceu entre os dias 12 e 27 de Outubro de 2021, e que teve abordagens aleatórias e investigativas objetivando a coleta dados socioepidemiológicos para a composição de informações complementares acerca dos conhecimentos e outras informações dos participantes, relacionadas ao tema estudado (descritas no item 2.4).

\subsection{Local do estudo e seleção da amostra}

A pesquisa foi realizada na Universidade da Amazônia (UNAMA), no Campus Alcindo Cacela, em Belém do Pará, Brasil. A Instituição de Ensino Superior (IES) está localizada na região metropolitana de Belém. Não houveram restrições quanto ao curso e ano dos acadêmicos participantes.

O número amostral foi de 100 participantes. Este número foi escolhido por melhor se adequar à disponibilidade financeira dos pesquisadores envolvidos, e pela reduzida quantidade de alunos que frequentam atualmente o campus, devido à pandemia do novo Coronavírus e à predileção pela universidade ao Ensino à Distância (EAD) no momento da pesquisa.

A pesquisa foi realizada nos turnos matutino e noturno de acordo com a disponibilidade dos pesquisadores. Em campo, os pesquisadores se dividiram em dois grupos: um grupo responsável pelo convite verbal aos alunos do campus (Grupo A), e outro grupo responsável pela recepção dos participantes e coleta dos dados socioepidemiológicos (Grupo B). Os pesquisadores do Grupo A abordaram aleatoriamente os estudantes que transitavam pelo campus, e, à medida que aceitavam o convite para participação na pesquisa, estes eram informados sobre o local de coleta dos dados, e para lá encaminhados imediatamente. Os 
pesquisadores lotados no Grupo B ficaram em sala, aguardando pela chegada dos participantes da pesquisa para então aplicarlhes os instrumentos para coleta de dados descritos no item 2.4.

\subsection{Critérios de inclusão e exclusão}

Os critérios de inclusão foram: a) possuir idade igual ou superior a 18 anos, b) ser estudante matriculado na Unama, Campus Alcindo Cacela, em qualquer turno.

Foram excluídos os participantes que: a) eram estudantes matriculados em outras unidades da Unama.

\subsection{Obtenção dos dados e coleta de amostras de sangue}

A obtenção dos dados foi realizada através da realização de teste imunocromatográfico e aplicação de um formulário socioepidemiológico criado pelos pesquisadores, que coletou informações tais como: idade, gênero, consumo de álcool, número de parceiros sexuais, condição socioeconômica, conhecimento prévio sobre o tema abordados neste estudo bem como sobre a relevância da pesquisa realizada, ciência de casos agudos ou fatais das doenças estudadas, bem como a opinião do participante em respostas pré-definidas a respeito da ocorrência e gravidade destas, e conhecimento sobre as formas de transmissão e características gerais dos vírus estudados pela presente pesquisa. A coleta dos dados sociodemográficos aconteceu imediatamente antes da realização do teste imunocromatográfico, em sala de aula disponibilizada pela Universidade.

Os participantes da pesquisa foram convidados a aguardar em fila do lado de fora da sala de coleta, onde, por ordem de chegada, eram chamados pelos pesquisadores do Grupo B para a coleta de dados e realização dos testes, um participante por vez.

O teste imunocromatográfico utilizado para a pesquisa foi da empresa Bioclin, lote 0082, fabricado em Julho de 2020 na cidade de Belo Horizonte - MG sob o número de registro na Agência Nacional de Vigilância Sanitária (ANVISA) 10269360307. Os testes e reagentes estavam dentro do prazo de validade no momento de sua realização.

O Teste Imunocromatográfico reagente para antígeno HBsAg foi performado seguindo as etapas abaixo;

a) Inicialmente, a escolha do dedo do Participante e a mão de sua preferencia (direita ou esquerda);

b) Higienização do dedo escolhido pelo participante com álcool 70\% e secagem do local com algodão estéril;

c) É realizada massagem e leve compressão no dedo que será puncionado para o acúmulo de sangue no local;

d) Com uma lanceta é perfurado o local no dedo de onde será retirada uma gota (aproximadamente 10 microlitros) de sangue periférico;

e) Um capilar é usado para coletar o sangue que em seguida será despejado no poço do dispositivo teste, que logo após é adicionado de duas gotas da solução tampão.

f) Para validação, é necessário que apareça a faixa "C" (Controle) no dispositivo de teste e, após esta aparição, se esperam aproximadamente 15 minutos para o resultado final do teste rápido, que em caso de amostra reagente, exibe corada em vermelho a faixa "T" (Teste).

\subsection{Análises dos dados}

Primeiramente, foram separados os testes negativos e os positivos; após isso, foram selecionados os questionários de acordo com a data da coleta de dados, em seguida, estes dados foram organizados em planilha digital na versão corrente do programa Microsoft Excel para organização e análise estatística. 


\subsection{Aspectos éticos da pesquisa}

Os indivíduos incluídos nessa pesquisa foram estudados segundo os preceitos da Declaração de Helsinque e do Código de Nuremberg, respeitando as Normas de Pesquisa envolvendo Seres Humanos conforme preconiza a resolução 466/2012 do Conselho Nacional de Saúde, garantindo os princípios bioéticos durante toda a pesquisa. Todos os participantes do estudo receberam esclarecimentos sobre a pesquisa e sua importância, e foram convidados a participar mediante leitura completa e assinatura do TCLE. Esta pesquisa foi aprovada pelo Cômite de Ética em Pesquisa da UNAMA com o n ${ }^{\circ}$ de parecer 5.030.830 emitido em 10 de Outubro de 2021.

\section{Resultados e Discussão}

Foram incluídas 100 pessoas no estudo, as quais realizaram, em sua totalidade, o teste de imunocromatografia para Hepatite B, onde 100 (100\%) testes mostraram resultado não reagente para presença do antígeno HBsAg. Em todos os ensaios, o material de teste utilizado foi rigorosamente averiguado pelos pesquisadores e pelo voluntário, em busca de quaisquer violações ou alterações visíveis a olho nu.

A maioria dos participantes desta pesquisa (56\%) é do sexo feminino, e a menor parte dos participantes (44\%) é do sexo masculino. Apesar de não haverem tido resultados positivos para casos agudos da Hepatite B, no Questionário Epidemiológico (QE), um total de $11 \%$ da amostra relataou já ter sido infectado pela Hepatite em algum momento da vida. A seguir, na Tabela 1, estão organizadas as respostas dos participantes quando perguntados no QE se já adoeceram em decorrência das hepatites A, B, C, D ou E.

Tabela 1 - Participantes que relataram a possibilidade de já terem tido algum tipo de Hepatite.

\begin{tabular}{lcc}
\hline Relato & $\mathrm{N}$ & $\%$ \\
\hline Positivo* & 11 & 11 \\
Negativo & 88 & 88 \\
Não respondeu & 01 & 01 \\
\hline Total & $\mathbf{1 0 0}$ & $\mathbf{1 0 0}$ \\
\hline
\end{tabular}

*Relato fornecido pelo participante sem confirmação diagnóstica. Fonte: Autores (2021).

A média de idade dos participantes da pesquisa foi de 27,5 anos; e o desvio padrão da amostra foi de 7,11. A maior ocorrência (frequência absoluta) foi a de participantes de 20 anos.

Buscando melhor entender o nível de informação dos participantes acerca do tema abordado, foi perguntado no questionário se estes já possuíam algum conhecimento prévio a respeito das hepatites (neste caso, todos os tipos: A, B, C ou E); os participantes também puderam informar se em suas famílias já haviam sido relatados casos de alguma possível hepatite. As respostas obtidas estão organizadas no Gráfico 1, a seguir. 
Gráfico 1 - Participantes que conhecem as Hepatites A, B, C, D, E; e que optaram por informar a possibilidade de ocorrência de algum caso de hepatite em sua familias.

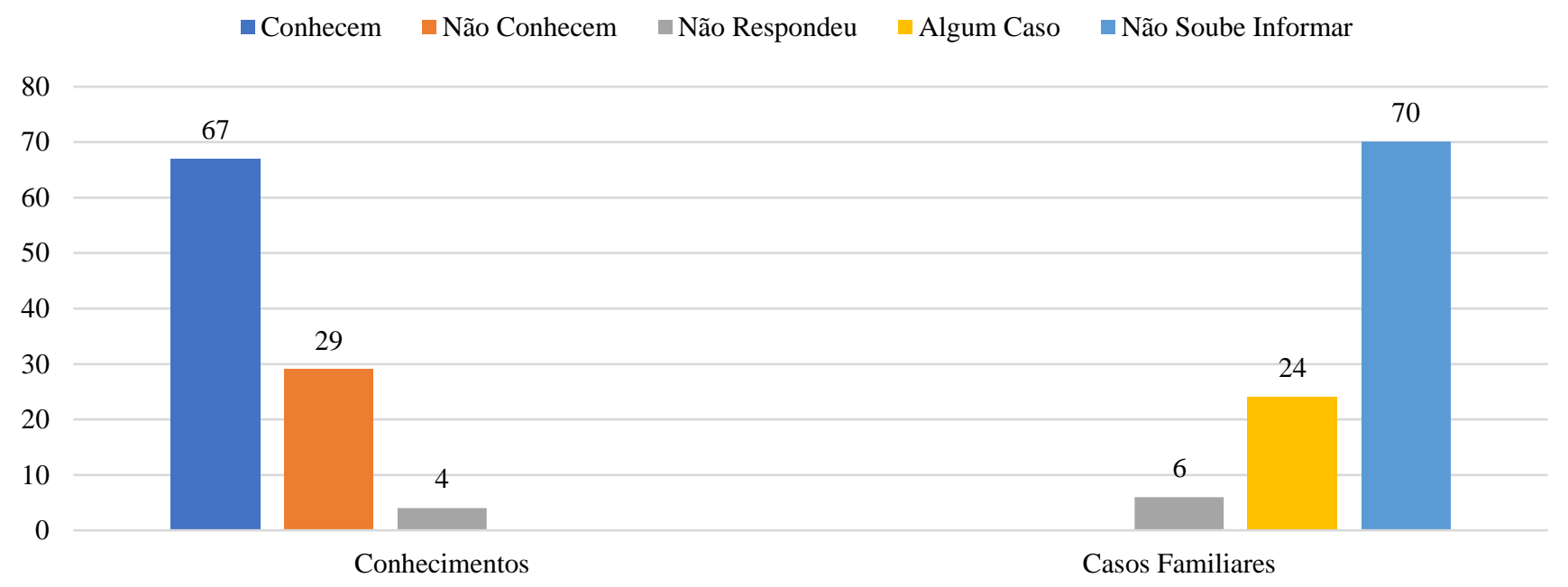

Fonte: Autores (2021).

Os participantes foram questionados sobre o que pensam a respeito da hepatite B, em respostas curtas pré-definidas pelos pesquisadores, afim de agrupar os resultados e ter um panorama mais uniforme sobre este dado tão variável; as respostas obtidas através do QE estão dispostas na Tabela 2, a seguir.

Tabela 2 - Opinião dos participantes acerca da hepatite B de acordo com respostas curtas pré-definidas pelos pesquisadores.

\begin{tabular}{lcc}
\hline Resposta & $\mathrm{N}$ & $\%$ \\
\hline Não sei, é uma patologia comum. & 14 & 14 \\
Não sei, é uma patologia rara. & 12 & 12 \\
Sei, e é uma patologia comum. & 60 & 60 \\
Não sei, é uma patologia rara. & 08 & 08 \\
Não respondeu. & 06 & 06 \\
Total & $\mathbf{1 0 0}$ & $\mathbf{1 0 0}$ \\
\hline
\end{tabular}

Fonte: Autores (2021).

Como pode ser visto na tabela acima, a maioria dos participantes acredita que a hepatite B é uma doença comum, mesmo que grave. Quanto a gravidade das hepatites, os voluntários da pesquisa foram questionados se tinham conhecimento de algum óbito que ocorreu em função de algum tipo de hepatite: $4 \%$ dos participantes afirmaram ter conhecimento de mortes decorrentes das hepatites, enquanto $62 \%$ responderam negativamente. Os outros $34 \%$ ficaram divididos entre os que não souberam responder com precisão (30\%) e os que preferiram não responder $(4 \%)$.

Os participantes também puderam optar por informar se possuem saberes básicos a respeito do patógeno em si e sua forma de transmissão e, ao analisar os resultados, assim como previsto, a população estudada possuía, no momento da coleta de dados, menos informações sobre o que é o Vírus da Hepatite D e como ele é transmitido entre pessoas quando comparado ao VHB. O gráfico abaixo mostra a disparidade entre estes dois dados com o objetivo de evidenciar o fato de que menos pessoas possuem conhecimentos sobre o vírus da hepatite D; e é muito importante observar com atenção que a seguir estão ilustrados apenas os resultados das pessoas que conheciam no momento da pesquisa ou a hepatite $\mathrm{B}$, ou a hepatite $\mathrm{D}$ individualmente. 
Gráfico 2 - Comparação entre os participantes que informaram ter conhecimento das hepatites B e D, de acordo com vírus causador e formas de transmissão.

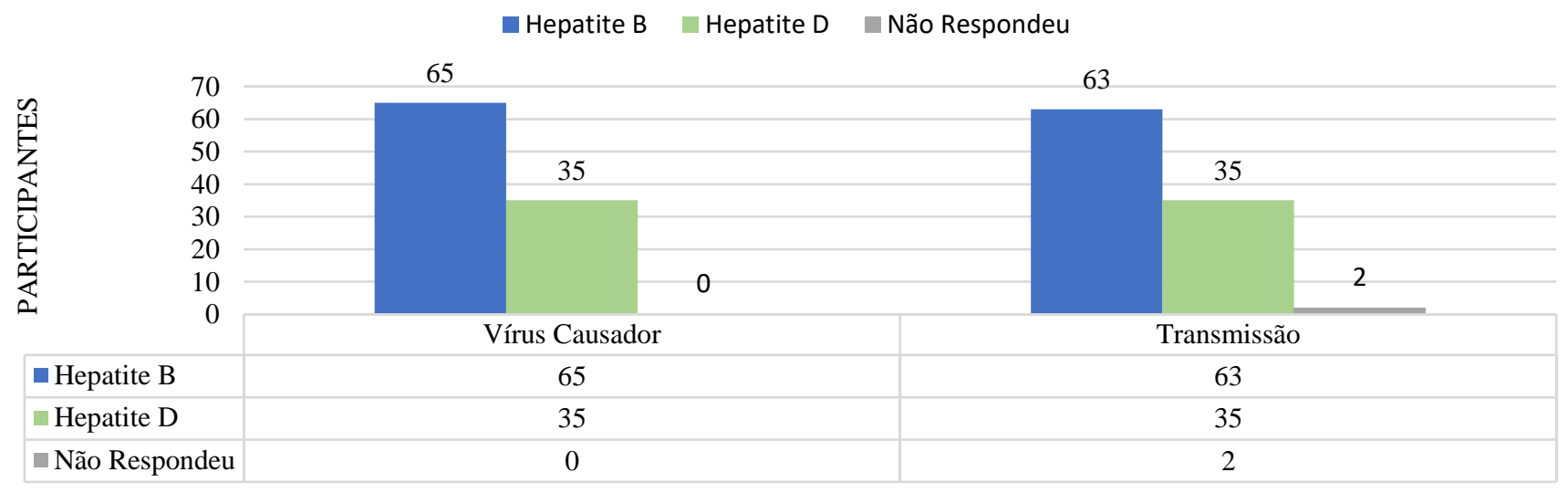

Fonte: Autores (2021).

Os participantes foram questionados no QE sobre a sua vida sexual; a maioria, 64 participantes (64\%) responderam que têm vida sexual ativa (VSA), 28 participantes (28\%) não têm VSA, enquanto apenas 8 participantes (8\%) optaram por não responder a esta pergunta.

Quando questionados sobre relações desprotegidas (RSDs), quase a metade da população estudada declarou ter tido RSDs nos últimos 6 meses: 47 participantes (47\%). O resto da população (53\%) ficou dividida entre os que optaram por não responder (3\%) e os que não tiveram RSDs (50\%) nos últilmos 6 meses.

É válido ressaltar que dentro do percentual de participantes que alegaram não terem tido RSDs nos últimos 6 meses, estão também agrupadas as pessoas que não têm VSA. Abaixo, dispostos no Gráfico 3, estão os dados sobre o número de parceiros sexuais por participante obtidos através do QE.

Gráfico 3 - Número de parceiros sexuais (p) dos participantes da pesquisa.

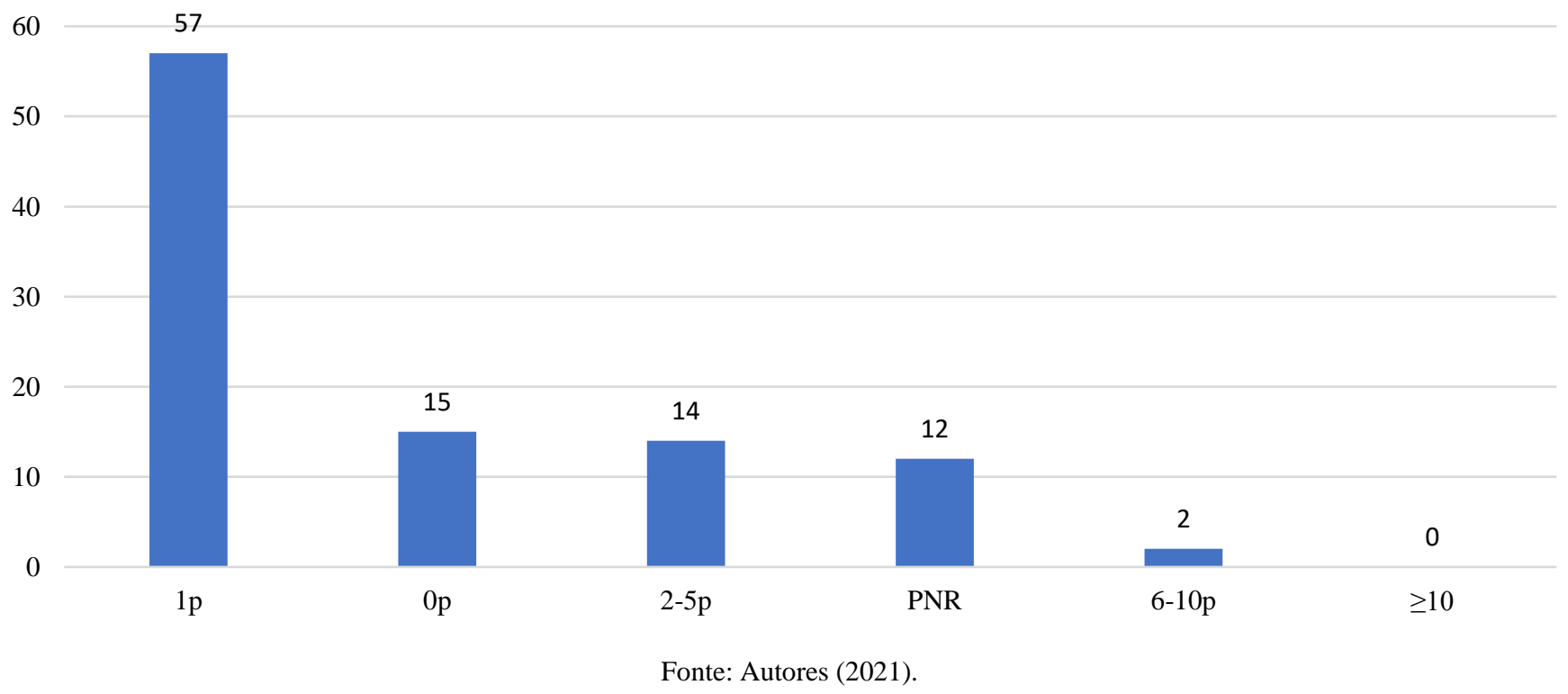

Foi questionado no QE perguntas sobre o estilo de vida dos participantes; caso consumissem bebidas alcoólicas os voluntários da pesquisa poderiam assinalar uma das questões presentes no QE. É de excelsa importância ter conhecimento do estilo de vida dos participantes neste sentido, já que a bebida alcoólica conhecidamente causa problemas no fígado, o órgão alvo 
dos vírus tratados nesta pesquisa. Mais da metade dos participantes (57\%) consome bebida alcoólica. Os outros $43 \%$ estão divididos entre 36\% que não consomem bebida alcoólica, e 7\% que preferiram não responder a esta pergunta.

No gráfico abaixo estão dispostos os dados relativos à frequência do consumo de bebida alcoólica pela população estudada.

Gráfico 4 - Frequência do consumo de bebida alcoólica pelos participantes que assinalaram consumir bebida alcoólica no QE.

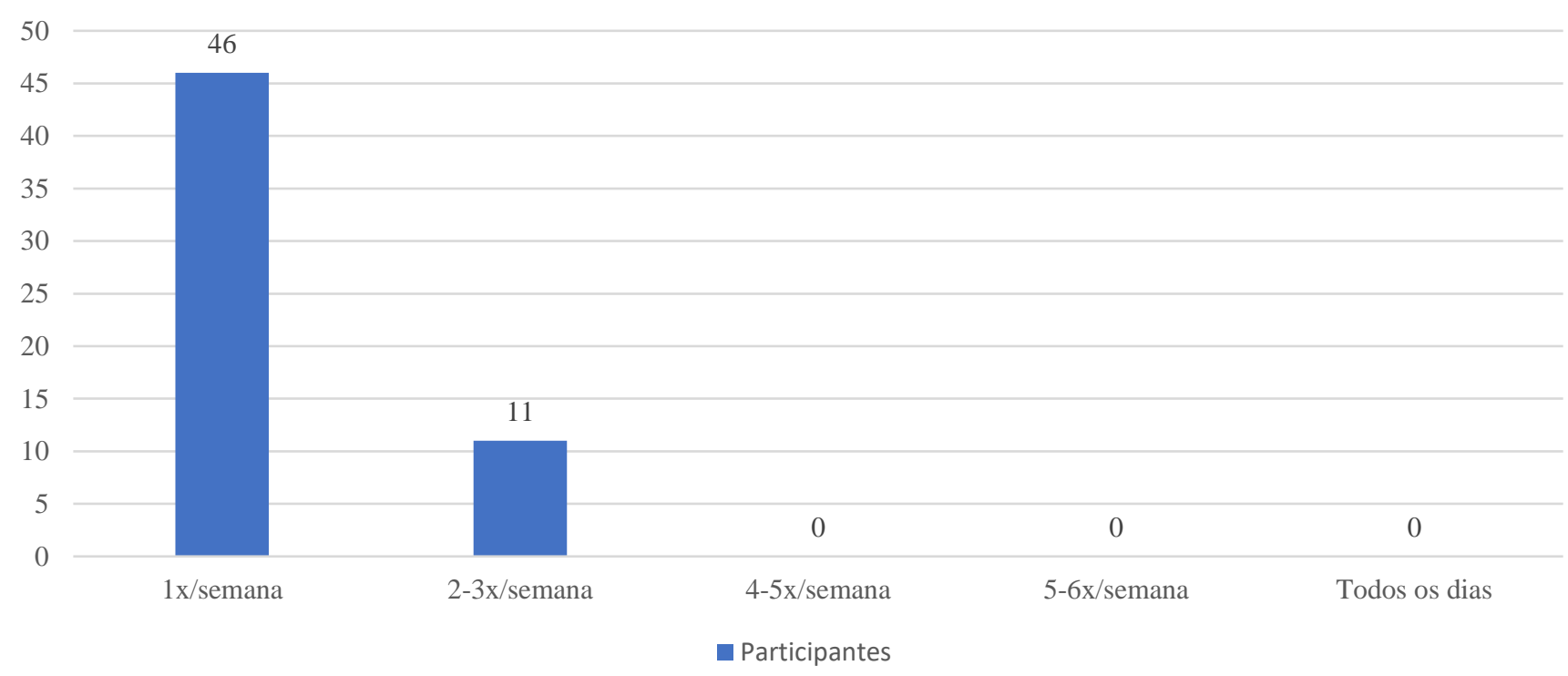

Fonte: Autores (2021).

Os participantes puderam opinar sobre a pesquisa em si, desse modo, a grande maioria (85\%) dos participantes acham que esta pesquisa é relevante, $10 \%$ declararam que esta pesquisa não é relevante, e apenas $5 \%$ da população optou por não responder se acham ou não esta pesquisa relevante.

Foi observado pelos pesquisadores que, no momento da coleta das amostras de sangue, os alunos ainda tinham dúvidas sobre o que eram as hepatites, em especial a HD. Este evento era esperado, haja vista a comprovada falta de informação das pessoas a respeito da gravidade das hepatites nos casos agudos e crônicos da doença. As dúvidas dos participantes variavam principalmente entre perguntas sobre a gravidade do hepatocarcinoma primário (câncer de fígado) e formas de transmissão da HD. Os resultados da pesquisa mostram que a maioria dos participantes conhece muito mais sobre o vírus causador e as formas de infecção da HB do que as mesmas informações sobre a HD.

De acordo com uma pesquisa realizada em 129 municípios brasileiros entre os dias 8 e 15 de Setembro de 2021 pelo Instituto Datafolha, encomendada pelo Instituto Brasileiro do Fígado (Ibrafig), onde 1.995 pessoas maiores de 18 anos participaram, a grande maioria da população acredita erroneamente que o câncer de fígado é uma doença secundária ao alcoolismo e tabagismo; ainda nesta sondagem, apenas $40 \%$ dos entrevistados pela pesquisa já haviam realizado qualquer tipo de testagem para as hepatites virais, mesmo que 8 em cada 10 Brasileiros tenham conhecimento de que a realização dos testes de hepatite B são realizados gratuitamente pelo Sistema Único de Saúde (SUS) através dos Centros de Testagem e Aconselhamento (CTA) (Instituto Datafolha, 2021; Ibrafig, 2021). A pesquisa trouxe nova perspectiva sobre as hepatites e como elas são vistas pela população acadêmica: de acordo com as respostas coletadas, em $60 \%$ da amostra observou-se um olhar desestigmatizado sobre a hepatite B (Tabela 2), e que no aspecto geral da doença, são conhecidas as formas de transmissão e características básicas da infecção (Gráfico 2).

De acordo com a Organização Mundial de Saúde (OMS), as hepatites virais são também caracterizadas como ISTs 
(OMS, 2021). Neste sentido, pode se presumir que, por exemplo, um parceiro pode infectar o seu cônjuge pelas hepatites de forma sexual; e de acordo com o Boletim Epidemiológico das Hepatites Virais de 2021, a maior parte das infecções (segundo provável mecanismo de infecção informado) aconteceu pelas vias sexuais: 21,3\% (54.103 casos). Além da forma viral da doença, se pode desenvolver de acordo com comportamentos e estilos de vida específicos, a forma não-viral da hepatite (Sung et al., 2021). Nesta pesquisa, os participantes puderam informar no QE casos de hepatites não-virais e virais (A, B, C, D e E) em suas familias ou conhecidos se assim desejassem: 24 participantes voluntariamente notificaram casos de hepatites que aconteceram nas suas famílias, enquanto 4 pessoas informaram conhecer alguém que faleceu em decorrência das complicações causadas por estas doenças.

Os casos crônicos de HB são a principal causa do hepatocarcinoma primário em países da América do Sul, e este câncer é o sexto mais comumente diagnosticado no mundo, onde as taxas de mortalidade e incidências são de duas a três vezes maiores em homens em relação à mulheres (Sung et al., 2021; Jemal et al., 2011), neste sentido, declararam já terem tido casos de hepatites mais homens que mulheres nesta pesquisa: 8 homens (72.72\%) e 3 mulheres (27.27\%), de um total de 11 participantes que confirmaram o contato prévio com a doença.

No Norte do Brasil, quando associados à infecções pelo VHD (em forma de coinfecção ou superinfecção) os casos agudos tendem a cronificar em um período de tempo muito mais diminuto (Cross et al., 2018).

A grande maioria dos participantes desta amostra consomem bebida alcoólica. O consumo destas bebidas é o principal fator de risco para o desenvolvimento da hepatite não viral, associado ao tabagismo e ingestão de compostos hepatotóxicos cumulativos como a aflatoxina (Sung et al. 2021; Hua et al., 2021).

A maioria da população estudada na presente pesquisa declarou ser sexualmente ativa, com uma variação entre um (01) a dez (10) parceiros sexuais nas respostas. Como publicado no Boletim Epidemiológico, o principal meio de contágio da Hepatite B no Brasil é a via sexual (Brasil, 2021), haja vista que de acordo com a OMS o vírus está presente no sangue e nos fluidos envolvidos no intercurso sexual como secreções vaginais e seminais (OMS, 2021).

A idade média dos participantes desta pesquisa foi de 27,5 anos e está dentro do previsto para o tema e população estudada. Verificou-se através de extensivas pesquisas que a hepatite acomete mais pessoas com idade entre 25 e 34 anos, no Brasil (Brasil, 2021).

É possível observar a partir deste estudo que a comunicação e posterior produção de material informativo sobre as hepatites, principalmente sobre a HD, se torna uma opção a ser considerada dentro do local de pesquisa estudado, já que de acordo com o Gráfico 2, é evidente a diferença entre as pessoas que conhecem mesmo que o básico das informações sobre a HB, e as pessoas que assim conhecem a HD: pouco mais que a metade dos voluntários da pesquisa que conhecem a HB, possuem algum conhecimento sobre a HD quanto ao vírus causador e as formas de transmissão desta doença.

Junto a estes dados, verifica-se a relevância do estudo de acordo com a opinião da comunidade: $85 \%$ dos entrevistados acham este trabalho de alguma forma útil para as suas vidas, enquanto apenas 10\% pensam que a presente pesquisa é irrelevante, e 5\% dos participantes não souberam ou não quiseram opinar se acham ou não a produção relevante.

\section{Conclusão}

Pode ser confirmado através deste estudo que a prevalência de casos agudos da coinfecção entre a HB e HD na população selecionada para esta pesquisa é nula. Alguns participantes afirmaram já terem tido casos de hepatite B, outros afirmaram ter presenciado casos de hepatites diversas em suas famílias e entornos.

É muito importante observar que a taxa de pessoas que conhecem a HB é maior que a taxa de pessoas que conhece a HD; a pesquisa concluiu que o motivo para essa discrepância se dá pelo pouco nível de informação da HD pelos participantes. 
Parte da população está em risco agravado de infecção pela HB por via sexual, e estar infectado por esta doença é o principal e único meio que permite com que a coinfecção pela HD se instaure agravadamente; evidencia-se também que além do risco sexual, mais da metade (57\%) dos participantes corre algum risco de desenvolver a hepatite não-viral através de um fator chave do estilo de vida: o consumo de bebida alcoólica.

Desta forma, recomenda-se que o local onde ocorreu a pesquisa, por concentrar pessoas em situação de risco para a aquisição destas infecções, invista em divulgação sobre as hepatites, em especial à HD devido à sua endemicidade que é elevada na região norte.

\section{Referências}

Alves, B., Gonçalves, M. B., Fontoura, L. V. \& Neves, G. D. (2017). Perfil Sexual de Estudantes Universitários. Revista Brasileira em Promoção da Saúde, 30 (4), 1-8.

Andrade, A. G., Duarte, P. C. A. V., Barroso, L. P., Nishimura, R., Alberghini, D. G. \& Oliveira, L. G. (2012). Use of alcohol and other drugs among Brazilian college students: effects of gender and age. Revista Brasileira de Psiquiatria, 34 (3), 294-305.

Beudeker, B., Voermans, J., GeurtsvanKessel, C. H., de Knegt, R. J., Kuhlemann, T., Boonstra, A., \& van der Eijk, A. A. (2021). Prevalence of hepatitis delta virus among chronic hepatitis B carriers in a large tertiary center in the Netherlands. Journal of clinical virology: the official publication of the Pan American Society for Clinical Virology, 141, 104870. https://doi.org/10.1016/j.jcv.2021.104870

Cardoso, L. R. D., Malbergier, A. \& Figueiredo, T. F. B. (2008). O consumo de álcool como fator de risco para a transmissão das DSTs/HIV/Aids. Rev. Psiquiatr. Clín. 2008; 35(1):70-75.

Castro, J., Almeida, C. \& Rodrigues, V. (2019). Atitudes e comportamentos sexuais de risco em jovens universitários. Revista Motricidade, 15 (4), $41-45$. https://doi.org/10.6063/motricidade. 20138

Departamento de Doenças de Condições Crônicas e Infecções Sexualmente Transmissíveis. (2021). Hepatite D. http://www.aids.gov.br/pt-br/publico-geral/hv/oque-sao-hepatites/hepatite-d.

Duarte, G., Pezzuto, P., Barros, T. D., Junior, G. M. \& Martínez-Espinosa, F. E. (2021). Protocolo Brasileiro para Infecções Sexualmente Transmissíveis 2020: hepatites virais. Epidemiologia e Serviços da Saúde, 30 (esp1), 1-8. https://doi.org/10.1590/S1679-4974202100016.esp1

Fonseca, J. C. F. (2002). Hepatite D. Revista da Sociedade Brasileira de Medicina Tropical, 35 (2), 181-190.

Hua, Z., Liu, R., Chen, Y., Liu, G., Li, C., Song, Y., Cao, Z., Li1, W., Li1, Lu, C. \& Liu, W. (2021). Contamination of Aflatoxins Induces Severe Hepatotoxicity Through Multiple Mechanisms. Frontiers In Pharmacology, 11 (605823), 6-11. https://doi.org/10.3389/fphar.2020.605823

Huang, C. R., \& Lo, S. J. (2014). Hepatitis D virus infection, replication and cross-talk with the hepatitis B virus. World journal of gastroenterology, 20 (40), 14589-14597. https://doi.org/10.3748/wjg.v20.i40.14589

Júnior, S. P. F., Rabelo, S. T. O., Lopes, E. M., Freitas, L. V., Pinheiro, a. K. B. \& Ximenes, L. B. (2007). Perfil e práticas sexuais de universitários da área da saúde. Escola Anna Nery Revista de Enfermagem, 11 (1), 58-65.

Magnius, L., Taylor, J., Mason, W. S., Sureau, C., Dény, P. \& Norder, H. (2018). ICTV Virus Taxonomy Profile: Deltavirus. Journal Of General Virology, 99, 1565-1566.

Ministério da Saúde, Secretaria de Vigilância em Saúde. (2019). Boletim Epidemiológico Especial. 19 (esp1), 35 -67.

Ministério da Saúde, Secretaria de Vigilância em Saúde. (2020). Boletim Epidemiológico Especial. 20 (esp1), $39-67$.

Ministério da Saúde, Secretaria de Vigilância em Saúde. (2021). Boletim Epidemiológico Especial. 21 (esp1), 35 -67.

Oliveira, C. M. A., Nunes, M. R. T., Nunes, H. M. \& Soares, M. C. P. (2012) Prevalência de marcadores sorológicos do vírus da hepatite B em profissionais de saúde de um laboratório de pesquisa na Amazônia oriental, Estado do Pará, Brasil, 2007 a 2009. Epidemiologia e Serviços de Saúde, 21 (4), $609-616$.

Rizzetto, M. (2015). Hepatitis D Virus: Introduction and Epidemiology. Cold Spring Harbor Perspectives in Medicine, 5 (1), 1-8.

Stockdale, A. J., Kreuels, B., Henrion M. Y. R., De Martel, C., Hutin, Y. \& Geretti, A. M. (2020). The global prevalence of Hepatitis D Virus infection: Systematic review and meta-analysis. Journal Of Hepatology, 73, 525-532. https://doi.org/10.1016/j.jhep.2020.04.008

Sung, H., Ferlay, J., Siegel, R.L., Laversanne, M., Soerjomataram, I., Jemal, A. \& Bray, F. (2021). Global cancer statistics 2020: GLOBOCAN estimates of incidence and mortality worldwide for 36 cancers in 185 countries. CA Cancer J Clin. 71, 209- 249. https://doi.org/10.3322/caac.21660

Urban, S., Neumann-Haefelin, C., \& Lampertico, P. (2021). Hepatitis D virus in 2021: virology, immunology and new treatment approaches for a difficult-totreat disease. Gut, 70 (9), 1782-1794. https://doi.org/10.1136/gutjnl-2020-323888

World Health Organization. (2021). Hepatitis B. https://www.who.int/en/news-room/fact-sheets/detail/hepatitis-b. 